\title{
A Pilot Study of Identifying Execution Plan Differences for Accelerated Bridge Construction
}

\author{
Elina Prajapati ${ }^{*}$ and Jin Ouk Choi ${ }^{2}$ \\ ${ }^{1}$ Graduate Student, Department of Civil and Environmental Engineering and Construction, \\ University of Nevada, Las Vegas \\ ${ }^{2}$ Assistant Professor, Department of Civil and Environmental Engineering and Construction, \\ University of Nevada, Las Vegas \\ *Corresponding author's email: elina.prajapati@unlv.edu
}

\begin{abstract}
Accelerated bridge construction (ABC) is an innovative construction technique used to accelerate the construction of new bridges, as well as the renovation/replacement of existing bridges. Due to the benefits offered by $\mathrm{ABC}$, transportation authorities have a higher preference in executing an accelerated approach over conventional bridge construction. The execution of an accelerated approach has differences when compared to the conventional approach, and it is important to identify such differences for the successful implementation of ABC projects. However, there have been no studies to identify such execution differences. Therefore, this study was conducted to identify execution plan differences relevant to ABC. For this purpose, an extensive literature review was conducted to prepare a preliminary list of execution plan differences. Then, a questionnaire survey was administered with the industry experts, who were previously involved in the execution of $\mathrm{ABC}$ projects, to validate the preliminary list. Based on the literature review and the responses from questionnaire survey, this study identified 61 execution plan differences relevant to $\mathrm{ABC}$ in different phases of execution. This study is expected to benefit owners, contractors, and road/bridge users for successful execution of $\mathrm{ABC}$ projects.
\end{abstract}

\section{KEYWORDS}

Execution Planning; Accelerated Bridge Construction; Offsite Construction for Bridge; Innovative Bridge for Rapid Renewal

\section{INTRODUCTION}

Bridges are an essential part of a transportation network for its proper functioning to provide for the crossing of rivers and lowlands. Therefore, timely construction or renovation/replacement of bridges is necessary to maintain an accessible road network. With the concept of modularization in construction, transportation authorities have widely implemented Accelerated Bridge Construction $(\mathrm{ABC})$ for construction of new bridges, as well as for renovation or replacement of old bridges in a transportation network. ABC shifts the majority of the site work to an offsite location, which results in a reduced onsite construction duration, and existing road users are less impacted. Compared to the conventional approach of bridge construction, the implementation of an $\mathrm{ABC}$ approach results in shorter construction duration, safer and more cost-effective execution of construction activities, and fewer traffic impacts (Culmo, 2011; Ralls, 2007). Further, ABC 
significantly improves the quality of construction work and the durability of bridges (HNTB, 2014).

Despite the many advantages of ABC (Choi et al., 2017), transportation authorities have not been able to understand all of the advantages provided by adopting ABC instead of using conventional bridge construction. Thus, researchers (Sakhakarmi et al., 2018) have developed a business case process to select between the accelerated and conventional approaches of bridge construction in order to assist decision makers in making the selection. However, differences exist related to project execution between the accelerated and conventional approaches. In the case of the industrial projects, CII research team 283 has already identified relevant execution planning differences in different phases of implementation (O'Connor et al., 2015), and it has supported the industrial sector for successful execution of these projects (O'Connor et al., 2014). Thus, there is a timely requirement to identify such differences for the successful execution of ABC projects as well. However, there has been no effort to identify such planning differences in different phases of project implementation for the execution of $\mathrm{ABC}$, compared to the conventional approach. Therefore, this study was conducted to identify the execution differences at different phases of implementing $\mathrm{ABC}$ projects, so that transportation authorities are able to execute such projects more successfully.

\section{OBJECTIVE}

The objective of this study is to identify the execution planning differences for implementation of $\mathrm{ABC}$ in transportation networks. The scope of this study is to review the execution plan differences for industrial projects, case studies on $\mathrm{ABC}$, and other technical documents, and then conduct a questionnaire survey to identify the planning differences relevant to $\mathrm{ABC}$. This study is expected to benefit owners, contractors, engineers and road/bridge users for successful implementation of $\mathrm{ABC}$.

\section{LITERATURE REVIEW}

It is obvious that the implementation of a modular approach has various execution planning differences in any construction work. These differences depend on the nature of the construction activities as well. For industrial modular projects, the CII research team (O'Connor et al., 2015) has identified 107 execution plan differences in different phases of project implementation. The execution plan differences in the selection phase include differences related to project objectives, organization and staffing, contract strategy, procurement, etc. Similarly, in the basic design phase, the execution differences include alignment of all parties, basic design standards, scope freeze, etc. The execution differences related to project control, site management, quality control, design deliverables, etc. are included in the EPC phase. Out of these 107 execution plan differences, 58 plan differences were identified to be relevant in the case of accelerated bridge construction.

Similar to the execution plan differences identified by CII for industrial projects, ABC has such differences in various project phases as well, such as planning and preconstruction, design, and construction. Detailed planning is required for the successful implementation of an ABC project (Beck, 2012). As ABC involves innovation in design and construction, there is a requirement of a pre-bid meeting between the owner, potential contractors, and suppliers to discuss potential options (Ralls, 2007) early in the planning and preconstruction phase. Prior experience of the owners, contractors, and designers in executing $\mathrm{ABC}$ projects plays a vital role in the early stages 
of project execution, and it is required that all parties have aligned mindsets (Basu, 2005; HNTB, 2014). Similarly, it is also required to have a meeting between the owner and contractor before the execution of the project to discuss methods of construction, challenges involved, and site tolerances (Banks, 2015; Basu, 2005).

The case studies on the implementation of $\mathrm{ABC}$ show that the use of innovative contracting, such as inclusion of incentive/disincentive clauses in contracts, and implementing project delivery methods such as lane rental, A + B bidding, design-build, and construction manager/general contractor (HNTB, 2014; Ralls, 2007, 2014) has resulted in successful execution of ABC. Further, the contract should offer a higher degree of flexibility to the contractor, which allows them to be innovative and creative, and possibly construct better and more quickly (Basu, 2005). In a case study, Yermack (2007) mentioned that the flexibility incorporated in the contract allowed the contractor and fabricators to modify the design, resulting in reduced cost and implementing the most efficient construction method. More importantly, there is a need for a higher level of communication between the owner, contractor, and fabricator (Basu, 2005) in all phases of project implementation. Similarly, there is a requirement of early procurement of construction materials such as girders, standardized components, and long lead items (HNTB, 2014; Ralls, 2007). The acquisition of permits and right-of-way earlier in advance during the planning phase (Basu, 2005; Ralls, 2007, 2014; Beck, 2012) are also execution differences, necessary to avoid delay in project execution. For transporting the bridge components and heavy equipment to the construction site, a transportation route planning is also required (Beck, 2012).

In the design phase, depending on the type of accelerated measures adopted for bridge construction, $\mathrm{ABC}$ might require designing an entire bridge or prefabricated bridge components (Banks, 2015; Ralls, 2007). The involvement of the contractor and specialty moving contractor in the design is important for successful execution of ABC (Harrington, 2014; Vanek, 2015). Additionally, the designer should be aware of the capability of the contractors involved in the project, and the material availability (Basu, 2005) for the suitable design of an entire bridge or modular bridge components. The design of ABC projects should also consider the use of highperformance construction materials to fabricate better quality, lighter weight, and smaller dimensional bridge modules (HNTB, 2014; Ralls, 2014). The dimensions and weights of bridge component modules are also guided by the transportation network capability, as well as equipment availability for transportation and lifting operations; therefore, the standardization of bridge module components should be considered in design (HNTB, 2014). Moreover, the design should incorporate tolerances for the placement of bridge components at the final location; the shop drawings for precast bridge components need to include a drawing of adjacent bridge components to avoid confusion during site installation (Banks, 2015). In addition, it is necessary to design the lifting diaphragms to facilitate site installation (Vanek, 2015). The success of an ABC project relies on proper coordination between the designer, fabricator, and specialty heavy lifting contractor to accelerate the production of critical bridge components, assure the timely procurement of long lead items, and plan for lifting operations (Vanek, 2015). The layout of on-site construction work, such as the position of the pile foundation and its elevation should be carefully planned to match the dimensions of the prefabricated components (Vanek, 2015). In addition, there is a requirement of more attention to engineering and manufacturing details, so that all precast components fit perfectly (Carter, 2007). 
During the construction phase, $\mathrm{ABC}$ allows contractors to perform parallel construction activities, which significantly decreases construction duration (Ralls, 2007). Further, the prefabrication of multiple bridge components results in a learning curve benefit that shortens the schedule as well (Carter, 2007). It requires quality control of the construction activities in every step (Bamrungwong, 2010). Thus, there is a requirement of a quality control unit at the fabrication yard as well as the construction site. The implementation of $\mathrm{ABC}$ also requires the use of innovative technology, such as self-propelled modular transporters (SPMT) to remove the existing bridge in case of replacement/renovation and to shift the prefabricated bridge to its final location quickly (Ardani, 2010; Beck, 2012; HNTB, 2014; Ralls, 2007). Depending on the ABC technique used, it might require the use of a hydraulic jacking system to slide the bridge into its final position (Ralls, 2014; Vanek, 2015). Additionally, ABC requires heavy lifting equipment, which necessitates designing a heavy lifting mechanism, as well as site stabilization, using geotechnical solutions for the foundation of such equipment (Beck, 2012). In a case study of replacing a bridge, Banks (2015) mentioned the requirement of using a large crane to place precast bridge components as the main difference between accelerated and on-site approaches to bridge construction. $\mathrm{ABC}$ allows for performing the final grading work prior to the installation of bridge (Banks, 2015). Finally, ABC requires the implementation of specialized abutment solutions (Beck, 2012). Hence, the literature review of case studies on $\mathrm{ABC}$ projects and technical reports on $\mathrm{ABC}$ shows that there are various execution plan differences required when implementing $\mathrm{ABC}$.

\section{METHODOLOGY}

The general approach of this study is to identify execution plan differences for ABC through an extensive literature review and questionnaire survey with $\mathrm{ABC}$ experts as shown in Figure 1.

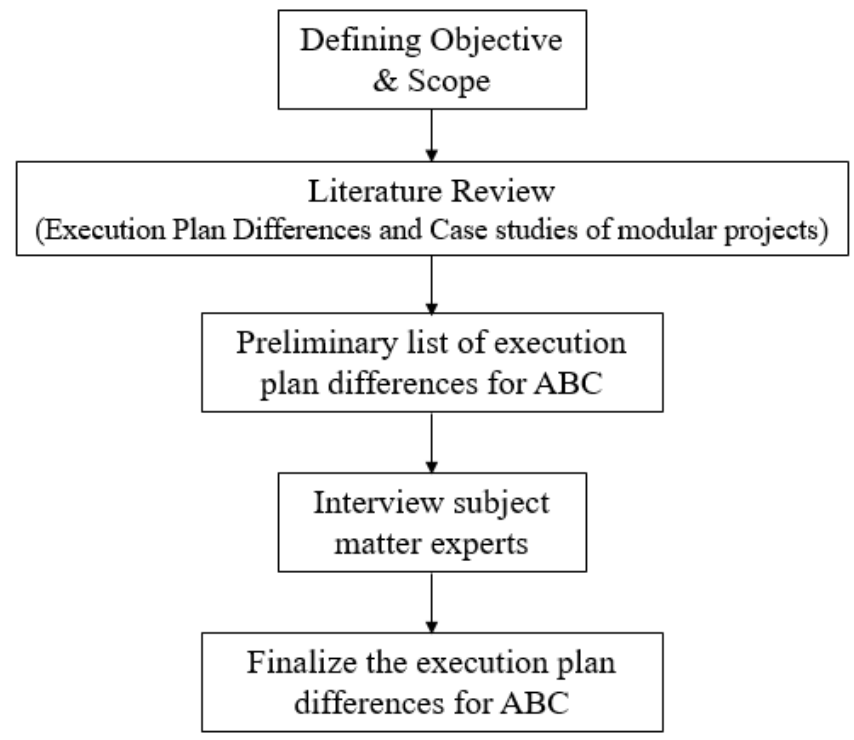

Figure 1. General Approach of the Study

The literature review included research articles related to execution planning differences between the modular approach and stick-built approach in industrial projects, case studies related to $\mathrm{ABC}$ projects, and other technical documents on $\mathrm{ABC}$. Based on the literature review, a preliminary list of 62 execution plan differences related to the implementation of $\mathrm{ABC}$ in different phases of project implementation was prepared. After that, interview in the form of online questionnaire 
survey was conducted with industry experts on $\mathrm{ABC}$ projects in order to validate the preliminary list of execution differences, and to make any required changes (additions/deductions) to the execution differences based on their responses. For the questionnaire survey, a set of questionnaires were prepared and sent to six subject matter experts, who were previously involved in the execution of $\mathrm{ABC}$ projects. The experts were asked to identify whether the execution differences listed in the preliminary list are relevant to $\mathrm{ABC}$ or not. They were also asked to note any additional execution plan differences, at different phases of project implementation, based on their experience. Furthermore, they were asked to list the top five most relevant and least relevant execution plan differences, based on their responses to previous questions. The preliminary list was updated to reflect the responses from the survey. Hence, a final list of execution plan differences related to the implementation of $\mathrm{ABC}$ projects is proposed as an outcome of this study.

\section{RESULTS}

The survey questionnaires were sent to four DOT Engineers and two contractors, out of which, only two DOT Engineers agreed to complete the questionnaires. Based on the responses, five execution differences, out of the preliminary 62 execution differences, were marked as not relevant to $\mathrm{ABC}$. Hence, these differences are excluded from the final list of execution plan differences. Similarly, the survey participants suggested four additional execution plan differences for ABC, which are included on the final list. Therefore, based on the literature review and questionnaire survey with industry experts, this study identified a list of 61 execution plan differences relevant to the execution of ABC. Following is the list of the 61 execution plan differences organized by the different phases of execution in $\mathrm{ABC}$ projects:

A. Planning and Preconstruction Phase

1. Requirement of detail planning for schedule, managing risk, and workaround solutions

2. Timely recognition of project objectives and their communication to all parties

3. Owner organization/staff appreciating modularization

4. Modularization coordinator to manage interfaces

5. Pre-bid meeting between the owner, potential contractors, and suppliers

6. Prior experience of the owners, contractors, and designers

7. Aligned mindset of all parties involved in the project

8. Pre-construction meeting between owner and contractor

9. Early formulation of contract strategies

10. Innovative contracting strategies: incentive/disincentive clauses, lane rental, $\mathrm{A}+\mathrm{B}$ bidding, design-build, and construction manager/general contractor

11. Alternative commercial agreements before fully defining the scope

12. Higher degree of contractual flexibility to the contractor and fabricators

13. For agency administering construction contract: importance of ability to reduce time needed to review contractor's temporary work designs to keep project on schedule

14. Higher level of communication between owner, contractor, and fabricator

15. Early procurement of materials such as girders, standardized components, and long lead items requiring earlier cash flow

16. Confirmation of special items before contract: supplied in a reasonable time or need to be obtained prior to the contract and provided to the contract as a way to reduce risk of delay

17. Need of increased owner/EPC resources and owner funding for early decision on procurement and commitments 
18. Pre-project authorization funding

19. Labor resource planning at fabrication shop as well as onsite

20. Timely identification of fabrication yard location in order to estimate transportation costs to final project location

21. Early acquisition of permits

22. Early acquisition of right-of-way

23. Transportation route planning

24. Identifying and addressing transportation corridor impacts

25. Any weather window consideration for transportation

26. Effective response to safety challenges: extreme-environment work, safety hazard exposure, etc.

27. Planning for module disassembly and subsequent reassembly, depending on type of $\mathrm{ABC}$ technique selected

28. Planning of on-site works to ensure accessibility of workers to module interfaces

B. Design Phase

1. Design of entire bridge or prefabricated bridge components depending on project requirement

2. Involvement of contractor and specialty moving contractor in design

3. Consideration of contractor capability and material availability

4. Use of high-performance construction materials for higher quality, lower weight, and smaller-sized fabricated units

5. Transportation network capability and equipment availability for transportation and lifting operations

6. Standardization of bridge module components

7. Owner design standards supporting accelerated approach

8. Use of advanced design modeling software to control module volumes and weights

9. Seismic design of details to join module meeting applicable codes: may require special research or scale model testing before moving forward

10. Design tolerance for placement of bridge components at a final location

11. Shop drawings for precast bridge components include a drawing of adjacent bridge components

12. Design of lifting diaphragms

13. Coordination between designer, fabricator, and specialty heavy lifting contractor

14. Planning of onsite construction works and equipment arrangement

15. More attention to engineering and manufacturing details

16. Requirement of early design freezing

17. Design outputs and completion schedule to support fabrication of modules, transportation, and site installation effectively

18. Constructability studies: method of construction, sequence and installation, transportation and heavy lift, temporary structures, etc.

C. Construction Phase

1. Parallel construction activities

2. Prefabrication of multiple bridge components: Learning curve benefit

3. Planning for cost, schedule, and quality control based on module-by-module 
4. Procurement and materials management systems capable of tracking materials and equipment at both fabrication yard and construction site

5. Productivity tracking and management at fabrication yard as well as construction site

6. Quality control at both fabrication yard and construction site

7. Interface management and communication between designer and fabricator

8. Formal preparation, reviewing, approval, and issuing of module fabrication tolerance control specification

9. Pre-shipment testing of prefabricated units

10. Module transportation instructions and specifications

11. Innovative technologies: Self-propelled modular transporters, hydraulic jacking system

12. Heavy lifting equipment: Design of lifting equipment and foundation stabilization using geotechnical solutions for foundation of such equipment

13. Use of large crane

14. Final grading works completed prior to bridge installation

15. Specialized abutment solutions

Based on the questionnaire response, the following is the list of the five most relevant execution plan differences for $\mathrm{ABC}$ :

1. Parallel construction activities

2. Constructability studies: method of construction, sequence and installation, transportation and heavy lift, temporary structures, etc.

3. Early procurement of materials: girders, standardized components, and long lead items requiring earlier cash flow

4. Requirement of detail planning for schedule, managing risk, and workaround solutions

5. Owner design standards supporting accelerated approach

Based on the questionnaire response, the following is the list of the three least relevant execution plan differences for $\mathrm{ABC}$ :

1. Early acquisition of permits

2. Use of high-performance construction materials for higher quality, lower weight, and smaller-sized fabricated units

3. Heavy lifting equipment: Design of lifting equipment and foundation stabilization using geotechnical solutions for foundation of such equipment

\section{CONCLUSION}

Transportation authorities are increasingly implementing an accelerated approach of bridge construction, which has many execution differences when compared to the conventional approach of bridge construction. The identification of such execution differences is very important for the successful execution of $\mathrm{ABC}$ projects. However, there have been no studies to identify such differences in execution of ABC. Thus, this research was conducted to identify execution plan differences relevant to the implementation of $\mathrm{ABC}$. Through an extensive literature review and questionnaire survey, this study identifies a total of 61 execution plan differences in different phases of implementing $\mathrm{ABC}$ projects. In the project planning and preconstruction phase, there are 28 execution plan differences. Similarly, in the project design and construction phases, there are 18 and 15 execution plan differences, respectively. However, the list of execution plan differences identified in this study needs to be validated through more interviews with experts involved in the 
MOC SUMMIT / MAY 2019

execution of $\mathrm{ABC}$ projects. Therefore, for future research, it is suggested to carry out an extensive survey to validate the list of execution plan differences.

\section{REFERENCES}

Ardani, A.A., Lindsey, R., and Mallela, J. (2010). "One-Weekend Job: Rapid Removal and Replacement of 4500 South Bridge in Salt Lake City, Utah." Journal of the Transportation Research Board, No. 2200, Transportation Research Board of the National Academics, Washington, D.C., 12-16.

Bamrungwong, C., Thongsom, J., Manokhoon, K., Binuma, W., Kijawatworawet, W., and Haleerattanawattana, P. (2010). "Accelerated Construction of a Medium-Span Bridge in Thailand with the Precast Segmental Approach." 2010 Structures Congress, 361-370.

Banks, G. A., Parrish, M., and Spry, C. W. (2015). "Replacing the Boeing North Bridge." PCI Journal, May-June, 29-38.

Basu, B. (2005). "Accelerated Construction and Rehabilitation of Bridges.” MS Thesis, University of Cincinnati.

Beck, C. (2012). "Accelerated Bridge Replacement." $<$ https://docs.lib.purdue.edu/cgi/viewcontent.cgi?referer=https://www.bing.com/\&httpsredi $\mathrm{r}=1 \&$ article $=1150 \&$ context $=$ roadschool $>($ Apr. 19, 2018)

Carter, J. W., Pilgrim, T., Hubbard, F. K., Poehnelt, T., and Oliva, M. (2007). "Wisconsin's Use of Full-Depth Precast Concrete Deck Panels Keeps Interstate 90 Open to Traffic." PCI Journal, January-February, 2-16.

Choi, J., Chen, X., and Kim, T. (2017). "Opportunities and Challenges of Modular Methods in Dense Urban Environment." International Journal of Construction Management.

Culmo, M. P. (2011). "Accelerated Bridge Construction - Experience in Design, Fabrication and Erection of Prefabricated Bridge Elements and Systems." U.S. Department of Transportation, Federal Highway Administration, FHWA-HIF-12-013.

Harrington, P.F., Khalil, R.Y., and Varney, J.C. (2014). "Rehabilitation of the Anderson Memorial Bridge." Proc., Structures Congress 2014, ASCE, Boston, Massachusetts, 723-733.

HNTB Corporation. (2014). "Innovation Bridge Designs for Rapid Renewal." Transportation Research Board.

O’Connor, J.T., O’Brien, W.J., and Choi, J. (2014). “Critical Success Factors and Enablers for Optimum and Maximum Industrial Modularization." ASCE Journal of Construction Engineering and Management.

O'Connor, J. T., O’Brien, W. J., and Choi, J. O. (2015). "Industrial Project Execution Planning: Modularization versus Stuck-Built." ASCE Practice Periodical on Structural Design and Construction, 21(1), 04015014.

Ralls, M. L. (2007). “Accelerated Bridge Construction.” ASPIRE, 1(2), 16-20.

Ralls, M. L. (2014). "History of ABC Implementation in U.S." National ABC Conference.

Sakhakarmi, S., Choi, J. O., \& Park, J. (2018). Business Case Process for Accelerated Bridge Construction. In International Road Federation Global R2T Conference \& Expo. Las Vegas, Nevada.

Vanek, C. M., Ryzhikov, V., and Khaleghi, B. (2015). "Restoring a collapsed span over the Skagit River.” PCI Journal, January-February, 52-66.

Yermack, E. (2007). "Accelerated construction of precast concrete piers on the Route 70 over Manasquan River Bridge Replacement Project." Innovations in Bridge Engineering Technology, 157-166. 